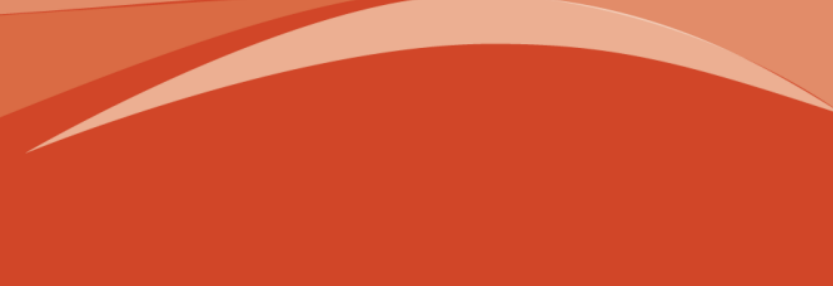

\title{
Por uma psicologia social morena: contribuições do pensamento de Darcy Ribeiro
}

\author{
For a brunette social psychology: contributions from Darcy Ribeiro
}

\section{Por una psicología social morena: contribuciones del pensamiento de Darcy Ribeiro}

\author{
Pedro Henrique Antunes da $\operatorname{Costa}^{\mathrm{a}} \mathbb{D}$; Fernando Santana de Paiva ${ }^{\mathrm{b}}$ \\ a Psicólogo, Mestre e Doutor em Psicologia pela Universidade Federal de Juiz de Fora (UFJF). Professor do Programa de Pós- \\ Graduação em Psicologia Social, da Universidade Federal da Paraíba (PPGPS/CCHLA), João Pessoa, PB, Brasil - E-mail: \\ phantunes.costa@gmail.com

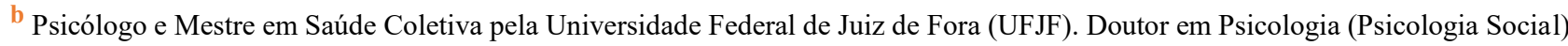 \\ pela Universidade Federal de Minas Gerais (UFMG). Professor de Graduação e Pós-graduação do Departamento de Psicologia da \\ Universidade Federal de Juiz de Fora, Juiz de Fora, MG, Brasil - E-mail: fernandosantana.paiva@yahoo.com.br
}

Resumo: O presente artigo objetiva sistematizar, preliminarmente, algumas aproximações e contribuições do pensamento de Darcy Ribeiro para a Psicologia Social latino-americana e, logo, brasileira. Trata-se de um estudo teórico enfocando o livro "O Povo Brasileiro: A formação e o sentido do Brasil", sua obra seminal, que abrange uma série de produções anteriores. O trabalho encontra-se estruturado em três partes: uma apresentação sumária do percurso acadêmico-político de Darcy e de pilares do seu pensamento; a explicitação de seus aportes para a Psicologia Social latino-americana; uma contextualização sobre a Psicologia Social e possíveis direcionamentos para o prolongamento desta relação. Consideramos que as contribuições do pensamento de Darcy para a Psicologia Social brasileira são: (a) O resgate da dimensão histórica na análise da realidade brasileira e dos sujeitos que aqui se conformam; (b) O caráter dialético dessa realidade; e (c) A transformação social como horizonte ético-político. Pensar numa Psicologia Social brasileira, ou uma 'Psicologia Social morena', inspirados no socialismo moreno de Darcy, implica na superação de sua própria ninguendade, por meio da aceitação de sua brasilidade. Uma Psicologia Social brasileira que, assim como necessita o seu povo, voltese cada vez mais para si, vivendo seu próprio projeto intelectual/acadêmico e prático e rompa com a sua miséria de dependência colonial.

Palavras-chave: Antropologia. Psicologia social. Brasil.

\begin{abstract}
This paper aims to systematize, in a preliminary way, some approximations and contributions of Darcy Ribeiro to the Latin American and, consequently, to Brazilian Social Psychology. This is a theoretical study focusing on the book "The Brazilian People: The Formation and Meaning of Brazil", his seminal work, which covers a series of previous productions. The work is structured in three parts: a summary presentation of the academic-political path of Darcy and the pillars of his thought; the explication of his contributions to Latin American Social Psychology; and a contextualization on Social Psychology and possible directions for extending this relationship. We consider that the contributions of Darcy to Brazilian Social Psychology are: (a) The rescue of historical dimension in the analysis of Brazilian reality and the people that conform it; (b) A dialectical character of this reality; and (c) Social transformation as an ethical-political horizon. To think of a Brazilian Social Psychology, or a 'Brunette Social Psychology', inspired by the brunette socialism of Darcy, implies overcoming its own nobodyness by accepting its Brazilianness. A Brazilian Social
\end{abstract} obra, forneça um link para a licença, e indicar se foram feitas alterações. 
Psychology that, as its people need, will turn more and more to itself, living its own intellectual/academic and practical project, breaking with its misery of colonial dependence..

Keywords: Anthropology. Social psychology. Brazil.

Resumen: El presente artículo objetiva sistematizar, de manera preliminar, algunas aproximaciones y contribuciones del pensamiento de Darcy Ribeiro a la Psicología Social latinoamericana y, por lo tanto, la brasileña. Se trata de un estudio teórico enfocando el libro "El Pueblo Brasileño: la formación y el sentido de Brasil", su obra seminal, que abarca sus producciones anteriores. El trabajo se encuentra estructurado en tres partes: una presentación sumaria del recorrido académico-político de Darcy y los pilares de su pensamiento; la explicitación de sus aportes para la Psicología Social latinoamericana; y una contextualización sobre la Psicología Social y posibles direccionamientos para la prolongación de esta relación. Consideramos que las contribuciones del pensamiento de Darcy a la Psicología Social brasileña son: (a) El rescate de la dimensión histórica en el análisis de la realidad brasileña y de los sujetos que aquí se conforman; (b) El carácter dialéctico de esta realidad; (c) La transformación social como horizonte ético-político. Una Psicología Social brasileña, o una 'Psicología Social morena', inspirada en el socialismo moreno de Darcy, implica la superación de ser ninguneo, por medio de la aceptación de su brasilidad. Una Psicología Social brasileña que, así como necesita su pueblo, se vuelva cada vez más para sí, viviendo su propio proyecto intelectual/académico y práctico y rompa con su miseria de dependencia colonial.

Palabras clave: Antropología. Psicología social. Brasil.

\section{Como citar o artigo:}

COSTA. P. H; A. PAIVA, F. S. Por uma psicologia social morena: contribuições do pensamento de Darcy Ribeiro.

Revista de Ciências Humanas, Florianópolis. v.52, 2018. DOI: 10.5007/2178-4582.2018.54111

\section{INTRODUÇÃO}

O presente artigo objetiva sistematizar, de maneira preliminar, algumas aproximações, contribuições e controvérsias do pensamento de Darcy Ribeiro para o campo da Psicologia Social latino-americana e, consequentemente, a realizada no Brasil. O pensamento de Darcy e sua preocupação com a formulação de uma teoria geral do Brasil pode contribuir para avançarmos e fortalecermos o campo da Psicologia Social, implicada com a compreensão e transformação da realidade brasileira, considerando suas raízes históricas, suas matrizes socioculturais que forjaram e deram sentido ao que chamamos de povo brasileiro.

Almeja-se, assim, contribuir também para processos de descolonização da Psicologia Social brasileira, mas sem cair, por um lado, em um extremismo que desconsidere tudo o que vem de fora, nos aportando de referenciais teóricos basilares para a compreensão da conformação histórica brasileira e suas implicações em nossa constituição material, mas também identitária e subjetiva ${ }^{1}$; e, por outro, em sucessivas tentativas de produção de conhecimento psicossociológico supostamente

\footnotetext{
${ }^{1}$ Lopez (1985, apud MARTÍN-BARÓ, 1987/2017), psicóloga porto-riquenha, denominou, criticamente, de "Psicologia do Coqui”, essa negação per si das teorias e métodos procedentes de outros países. O Coqui é uma pequena rã que existia somente em Porto Rico, um dos símbolos do país. A partir dessa ilustração, Martín-Baró formula a terminologia "Psicologia Nacionalista" e postula a necessidade de fomentarmos um nacionalismo latino-americanista, superando a condição de dependência e vassalagem aos Estados Unidos, mas sem cair num patriotismo vazio, que muito se assemelha com projetos de setores dominantes racistas e xenófobos.
} 
genuíno e inovador, mas que desconsidera todo o acúmulo de conhecimento já possibilitado pelo desenvolvimento das Ciências Sociais, bem como do pensamento social brasileiro em geral. Não obstante, busca-se rememorar a posição da própria Psicologia Social no âmbito das ciências humanas e sociais e a sua insuficiência enquanto campo autocentrado e isolado das outras disciplinas que também se ocupam na compreensão e explicação do sujeito brasileiro.

Para atingir o objetivo mencionado, o trabalho encontra-se estruturado em três partes: (a) apresentação de maneira sumária do percurso acadêmico e político de Darcy Ribeiro, juntamente com alguns dos pilares de seu pensamento; (b) explicitação das possíveis contribuições do pensamento darcyniano para a Psicologia Social brasileira; (c) contextualização sobre a Psicologia Social brasileira e latino-americana e algumas considerações e possíveis direcionamentos para o prolongamento desta relação.

Cabe ressaltar que, devido à amplitude da produção de Darcy Ribeiro, não havendo, portanto, a possibilidade de exprimir em um só trabalho deste porte todo o seu relevo e contribuição, optamos por focar no livro “O Povo Brasileiro: A formação e o sentido do Brasil” (RIBEIRO, 1995/2006), sua obra seminal, que abrange e aprofunda uma série de produções anteriores, sendo considerada por ele mesmo como o maior desafio a que se propôs fazer e ao qual mais se empenhou (RIBEIRO, 1995/2006). Ou seja, se há uma obra que mais se aproxima do esforço ao qual se propôs o pensador brasileiro, de postular uma teoria geral do Brasil, seria este livro. Para traçar um pouco de seu percurso histórico e motivações político-acadêmicas, nos valemos também de literatura secundária sobre o autor e seu pensamento e de textos oriundos do próprio Darcy, comentando sobre sua vida e obra.

\section{DARCY RIBEIRO E SUAS PELES}

Impossibilitados de efetuarmos uma profunda apresentação de uma trajetória repleta de contribuições e realizações, traçaremos um breve perfil de Darcy Ribeiro, buscando conhecer não apenas a pessoa, mas as influências teóricas e motivações em sua produção intelectual, de modo a substanciar seus aportes para a Psicologia Social brasileira. Dono de uma vida bastante atribulada, Darcy (1922-1997) se dizia dotado de várias peles, as quais alternou no decorrer de sua vida, desafiando um suposto destino que nos havia sido imposto, uma sina de dominação, exploração e atraso (RIBEIRO, 2015). Para isso, encarnou peles de intelectual, educador, romancista, político, de acordo com suas necessidades e das carências que vislumbrava.

Sua vasta produção acadêmica perpassa e estabelece diálogos entre várias áreas e disciplinas do conhecimento, mas é, sobretudo, em sua Antropologia dialética, que ao longo do tempo incorpora a perspectiva de um marxismo não dogmático (RIBEIRO, 1995/2006; 2015), sob a qual residem as 
principais contribuições do autor para o pensamento social brasileiro. Destacamos, dentre suas obras, as seguintes: O processo civilizatório (1968), Os índios e a civilização (1970), As Américas e a civilização (1970), O dilema da América Latina (1979) e O Povo Brasileiro: A formação e o sentido do Brasil (1995).

De acordo com Vasconcellos (2015), Darcy Ribeiro foi o cientista social brasileiro mais "antieurocêntrico", ou o que mais se "latino-americanizou", devido ao seu desejo e ação pela integração latino-americana sob a forma da Pátria Grande e à sua intencionalidade de compreender as particularidades dos países que conformam nosso continente. Este desejo e trabalho foram potencializados em suas incursões e distintas contribuições (políticas, educacionais etc.) em países como Uruguai, Argentina, Chile, Venezuela e Peru, durante o seu exílio imposto pela ditadura militar brasileira.

Indubitavelmente, a escolha de Darcy Ribeiro não se dá por obra do acaso ou motivada somente pela sua produção intelectual na compreensão sobre quem somos e como nos formamos processualmente. Outros autores também se empenharam desta árdua tarefa. $\mathrm{Na}$ impossibilidade de abrangermos esta totalidade e na indispensabilidade de nos pautarmos por uma consistência teóricoconceitual, devemos fazer escolhas, que, neste caso, estão atreladas, sobretudo, ao caráter latinoamericanista e não-colonizado (anti-imperialista) de Darcy e sua obra. Estes atributos, em nossa concepção, são fundamentais para refletirmos sobre uma Psicologia Social que seja brasileira não só por se fazer aqui, ou por empreender condenações vazias a que(m) discorde, mas que se ocupe com a realidade e os sujeitos que aqui se põem, de modo não só a compreendê-la, mas também a transformá-la, o que significa autocrítica.

Portanto, da mesma forma como irão coexistir os vários Brasis (do índio, da matriz portuguesa, dos negros africanos, o crioulo, o caboclo, o sertanejo, o caipira, os sulinos), conformando uma unidade múltipla brasileira, teremos vários Darcys: o antropólogo, o lutador da educação e "plantador de centenas de boas escolas e modernas universidades" (RIBEIRO, 2015, p. 15), o romancista e o político; diversos, mas que se unem justamente no afeto ao povo brasileiro, em especial aqueles açoitados pelo rolo compressor que foi (e é) nossa constituição como país-nação, buscando compreender este processo, bem como transformar nossa realidade. Assim, sincreticamente, conformam uma unidade, chamada Darcy Ribeiro. 


\section{CONTRIBUIÇÕES DE DARCY RIBEIRO PARA SE PENSAR O BRASIL}

\section{O RESGATE DA DIMENSÃO HISTÓRICA (NA ANÁLISE SÓCIO ANTROPOLÓGICA)}

Para compreender tanto o Brasil quanto essa gente que aqui se fez/faz, é necessário rememorarmos nossas origens, o que nos remete ao nosso histórico de formação sociocultural. Nesse sentido, a primeira contribuição de Darcy Ribeiro para a Psicologia Social brasileira se refere à necessidade do resgate dessa dimensão histórica na conformação da realidade e do sujeito brasileiro, ao invés da utilização de chaves de compreensão a-históricas que desconsiderem sua dinamicidade e as condições de existência pelas quais estes sujeitos se produziram e continuam a se produzir. Conforme aponta Miglievich-Ribeiro (2009), nada há de natural e de estático na conformação de um povo, o que nos leva a pensar em processo, isto, é, na história e seres como processos.

Não obstante, tal pressuposto nos convida a analisar e compreender nossa constituição material e subjetiva, assim como nossa sociabilidade, imbuídas em processos de segregação étnicoracial e antagonismos de classe - tomados como estruturantes na orquestração de nosso país e ordenamento social. Nesta direção, é importante destacar a retomada por ele do conceito de atualização histórica para nomear o processo civilizatório brasileiro que, segundo ele interrompe "a linha evolutiva prévia das populações indígenas brasileiras” e, “depois de subjugá-las, recruta seus remanescentes como mão-de-obra servil de uma nova sociedade, que já nascia integrada numa etapa mais elevada de evolução sociocultural" (RIBEIRO, 1995/2006, p. 67). Trata-se de um processo caracterizado pela edificação de uma relação pautada na dependência/subordinação dos latinos colonizados, atrasados em termos de sistemas tecnológicos (o que não implica em nenhum grau de inferioridade, conforme defendia o Evolucionismo Social e seu etnocentrismo) e que "supõe a perda de autonomia étnica dos núcleos engajados, sua dominação e transfiguração” (RIBEIRO, 1995/2006, p. 67).

Dessa forma, é recusada a ideia de que existe uma sequência evolutiva linear e hierárquica, que tomava as sociedades não-europeias como estágios primitivos de civilização. Pelo contrário, Ribeiro compreende a evolução humana de modo multilinear, a partir de uma pluralidade de formações socioculturais concretas, perpassada por uma série de rupturas e contradições. $\mathrm{O}$ caso brasileiro (representado pelo conceito de atualização histórica) caracterizou-se pelo contato conflituoso entre os polos dominador e dominado, ocasionando um cenário de transfiguração étnica, onde apesar dos indígenas manterem sua identidade indígena, alguns de seus costumes, cultura e modos de viver, foram modificados forçadamente em prol da sobrevivência num contexto e civilização hostil (MIGLIEVICH-RIBEIRO, 2011). Ademais, para Darcy, é no desenvolvimento 
tecnológico, isto é, na evolução dos meios de produção e reprodução das condições de existência, que reside o elemento propulsor do processo civilizatório (VASCONCELLOS, 2015). Aliado a este pilar de edificação, estariam outros dois planos: as bases associativas, que dizem respeito aos modos de organização da vida social e econômica, abarcando força de trabalho e luta de classes; e os elementos ideológicos, relativos às formas de comunicação, saber, valores compartilhados, que impactam na autoimagem étnica.

É a partir dos profundos processos de estratificação, desigualdade social e diversas opressões, materializados nessa história de colonização, dependência, exploração, escravidão - e que se fortalecem nos modos injustos de produção e distribuição da riqueza socialmente produzida -, que se conformam os sujeitos que neste "criatório de gente" (RIBEIRO, 1995/2006, p. 72) se inserem e se fazem. São sujeitos coletivos que passam por processos de dominação e opressão, que além de agregarem consigo efeitos negativos imanentes, ainda contribuem para o seu assujeitamento, com naturalização e internalização destes processos, impactando diretamente em diversos âmbitos de sua vida, desde sua subjetividade e identidade social até a forma como estabelecem suas relações entre si e com o mundo (MARTÍN-BARÓ, 1985/1996).

Sujeitos que trazem consigo física e simbolicamente, objetiva e subjetivamente, as marcas desse processo, a partir da própria configuração societária que se constituiu em função destas mediações, se valendo delas para categorizá-los e reduzi-los, impossibilitando-os de fruir de sua potência e liberdade (MARTÍN-BARÓ, 1986/2011; 1987/2017). Conforme Darcy:

\begin{abstract}
Nós, brasileiros, somos um povo em ser, impedido de sê-lo. Um povo mestiço na carne e no espírito, já que aqui a mestiçagem jamais foi crime ou pecado. Nela fomos feitos e ainda continuamos nos fazendo. Essa massa de nativos oriundos da mestiçagem viveu por séculos sem consciência de si, afundada na ninguendade [...] Um povo, até hoje, em ser, na dura busca de seu destino (RIBEIRO, 1995/2006, p. 410)
\end{abstract}

Ademais, é voltando nessas raízes, que podemos compreender os contínuos moinhos de gastar gente, que perfazem nossa construção étnica e configuração social desde a feitoria invasora e escravista que aqui se instaurou, passando pela expansão do domínio português como obra também dos próprios brasilíndios, germinados no berço do cunhadismo. Uma nova etnia e identidade brasileira, mestiça, brasilíndia, que ao ser fundada em processos não só de aculturação, mas de deculturação, de negação de sua própria ancestralidade, quase como tábuas rasas, produz tipos psicológicos que nesse vazio tornam-se “impositores da dominação que os oprimia” (RIBEIRO, 1995/2006, p. 97). Em suma, os opressores nas peles de oprimidos, numa relação constante, conflitiva e não dicotômica entre dominador e dominado.

Afinal, como explicar as origens desse nosso sentimento de inferioridade em face ao restante do mundo, principalmente com o hemisfério norte (Estados Unidos e Europa), senão perpassada por 
estes processos? E a nossa reiterada mistura de resignação, fatalismo e passividade frente às condições sociais injustas e opressoras? Os próprios dados e a realidade de encarceramento em massa, de cenário de guerra e extermínio, a atuação truculenta da polícia com os seus semelhantes, os linchamentos (físicos e simbólicos) cada vez mais frequentes, todos estes macetando em especial negros e pobres, seriam reconfigurações destes processos constantes de moer gente, intensificados por um modelo de sociedade que mercantiliza e, consequentemente, desumaniza as necessidades humanas; uma ordem social que nos aliena dos outros e de nós mesmos, e que, ao nos negar enquanto seres humanos, nos leva a um processo de coisificação.

Vale apenas ressaltar que, para Darcy, o conceito de mestiçagem e sua importância na configuração social e étnica do Brasil não implica numa desconsideração dos nossos antagonismos de classe e raciais estruturantes (que não podem ser compreendidos de maneira dissociada). Este é um conceito bastante debatido e criticado em outras perspectivas de descolonização do pensamento, sobretudo, em movimentos intelectuais e ativistas não-brancos, por conta da forma como historicamente foi utilizado, de modo a apresentar um país homogêneo e uma identidade nacional estruturada e percebida aos/pelos olhos, costumes etc. dos brancos. Não significa, portanto, compactuar com uma lógica e política de branqueamento, ou de democracia racial (a qual ele se opõe, conforme iremos sinalizar posteriormente), onde as categorias "povo brasileiro" ou de "brasilidade" apagariam ou silenciaram as diferenciações raciais e classistas existentes, corroborando para a perpetuação das estruturas racistas e de antagonismo de classe.

Assim, de acordo com a perspectiva defendida por Ribeiro, uma explicação das contradições e desigualdades sociais unicamente pela via da cultura ou da transmissão de valores, vide perspectivas teóricas embebidas no culturalismo, mostra-se insuficiente, pois desconsidera todo seu atrelamento a essa dimensão concreta e objetiva marcada pela escravidão e colonização sob o desígnio do capital em sua marcha de exploração no Brasil, América Latina em geral e outros contextos. O que vemos, então, é a continuação de uma lógica em que uns valeram e valem menos que outros.

\section{O CARÁTER DIALÉTICO DA REALIDADE BRASILEIRA}

Atrelada à dimensão histórica, outra contribuição do pensamento darcyniano para a Psicologia Social brasileira incide na constatação do caráter dialético da realidade. Essa dialeticidade pode ser observada de distintas formas. Um primeiro ponto, conforme postulado por ele, trata-se da indissociação entre o velho e o novo em nosso processo de gestação como povo e construção identitária. Isto é, o povo brasileiro é um "povo novo", mas em diálogo constante com o velho, um “renovo mutante" (RIBEIRO, 1995/2006, p. 18). Um povo que, apesar de gestado por invasores, 
atado aos seus colonos portugueses genética e, sobretudo, econômica e politicamente, é uma etnia nacional, ao mesmo tempo que composto por uma vasta gama de etnias, diferente de sua matriz formadora. Nossa origem está ancorada no processo de exploração escravista da força de trabalho indígena e negra, como forças motrizes e principais ferramentas de expansão econômica, ao passo em que tratora e/ou renega este histórico, possuindo como elemento nevrálgico para a sua constituição sociocultural e identitária os processos de desindianização do índio e desafricanização do negro.

Logo, o próprio brasileiro se faz nesse caldeirão, onde as singularidades de cada um se atrelam aos aspectos universais de nossa totalidade e sociabilidade, mediados pelas particularidades que cimentam a vida social e conformam a vida de cada sujeito: condições socioeconômicas, classe, gênero, raça/etnia etc. (PASQUALINI; MARTINS, 2015). Outros elementos dessa constituição dialética de nossa realidade dizem respeito às determinações reflexivas entre diversidade e unidade. Por exemplo, somos um país-nação e um povo, que apesar de conformados por uma variedade de matrizes formadoras, de diferentes culturas, constituímos uma "etnia nacional, um povo nação" (RIBEIRO, 1995/2006, p. 19). Ao falar dessa unidade, Darcy faz uma comparação com outros contextos onde, diferentemente do Brasil, essa unidade nacional, no âmbito político, foi perpassada por inúmeros conflitos, guerras, movimentos separatistas etc. entre grupos, etnias e povos. Nesse sentido, a própria concepção de unidade ou uniformidade, ou mesmo a de brasileiro, não significa desconsiderar os antagonismos de classe, étnico/raciais, de sexo e gênero, dentre outros; pelo contrário, compreender que, em parte essa uniformidade se dá, por um lado, pela imposição por meio da repressão e coerção física, e, por outro, na anulação e naturalização destas diferenciações em prol da manutenção da ordem que suprime uns aos outros. Ademais, temos também uma extensão e dimensão geográfica continental que contribui para a existência de uma paisagem multifacetada, com múltiplos biomas, permeada por inúmeras formas de existência e sobrevivência, e que, ao mesmo tempo, servem como resistências a um mundo e modo de vida cada vez mais homogêneo, urbanizado e globalizado.

Continuando nessa direção, pensar a realidade brasileira dialeticamente também significa colocar em perspectiva - consonante com o resgate da análise histórica - o seu caráter de permanente contradição e tensão. Com isso, é problematizada nossa constituição étnica e sociocultural assentada na mestiçagem, mas que foi e é forjada na usurpação e domesticação do negro e do índio; portanto, que rompe com a lógica de que somos todos iguais por sermos "mestiços"; uma exploração que, apesar de bárbara, é contada de maneira pacífica e romantizada, que ainda é naturalizada e concebida como um dos argumentos ideológicos para uma suposta igualdade. Como resultado, em contraposição ao mito das três raças e da Democracia Racial, teríamos, segundo Darcy, uma subtração ao invés de 
soma, uma terra arrasada, uma ninguendade ${ }^{2}$ de não-índios, não-europeus e não-negros, de onde surge o mestiço, o brasilíndio, isto é, essa nova identidade étnica brasileira (ARRUTI, 1997).

O brasilíndio como o afro-brasileiro existiam numa terra de ninguém, etnicamente falando, e é a partir dessa carência essencial, para livrar-se da ninguendade de não-índios, nãoeuropeus e não-negros, que eles se veem forçados a criar a sua própria identidade étnica: a brasileira (RIBEIRO, 1995/2006, p. 118).

Dessa forma, podemos refletir sobre a nossa unidade cultural retratada nos dias atuais, que se ancora em lógicas de supostas aceitação e inclusão materializadas em processos de violência, segregação e marginalização sociais e que se valem dessa sua pluralidade, desde que se possa mercantilizá-la, como, por exemplo, o que aconteceu e acontece com os indígenas, negros e elementos de suas culturas. Conforme postula Darcy, uma unidade nacional calcada num antagonismo de classes racista que opõe a maioria da população aos desígnios de uma minoria dominante e poderosa e que mantém seu projeto social na base do suor e sangue dos primeiros. Existe em nosso país um abismo social tão exacerbado que, muitas das vezes, se assemelha a um sistema estático de castas, mas que se disfarça sob o véu ideológico da democracia racial ou da lógica liberal-burguesa das possibilidades da iniciativa individual e da meritocracia. Em suma, entendemos, por um lado, que estes processos são contraditórios, o que não significa uma aceitação pacífica de suas existências, até porque são "praticamente um estado de guerra latente" (RIBEIRO, 1995/2006, p. 153), pois acomodam feridas, cujas cicatrizes encontram-se hoje ainda presentes, afinal são estruturais, conformando quem nós somos, como nos vemos, nos relacionamos e agimos frente à essa realidade. E, por outro, de que em condições permanentes de disputa não há homeostase, ou uma suposta cordialidade, e que assumir neutralidade é advogar pelo dominante e corroborar para a manutenção do status quo.

De modo geral, estes aspectos aparecem atrelados diretamente com a necessidade de compreensão das noções de sujeito e sociedade de forma processual e dialética, indo para além de uma mera influência mútua entre ambos, mas entendendo-os constitutivos um do outro e implicados entre si a partir de uma intersecção, forjando-se pela práxis humana. Os sujeitos, isto é, os brasileiros e as brasileiras, em suas inúmeras singularidades que se fazem em meio a esta totalidade e suas mediações com as particularidades sociais, aparecem, portanto, como produtos e produtores desse processo histórico, o que explicita fundamentalmente o seu caráter sociocultural e histórico, a partir do momento em que os consideramos, assim como os contextos aos quais eles se inserem e que lhes constituem, como vivos, dinâmicos, em constante mutação.

\footnotetext{
2 Termo próximo à "ningunear" e "ninguneo" cunhados pelo escritor mexicano Octavio Paz em seu livro "El labirinto de la soledad", de 1950. Na Psicologia Social latino-americana, Martín-Baró (1985/2017, p. 37) também utiliza o termo "ningunear" para se referir aos camponeses de El Salvador, denominados por ele de "condenados da terra".
} 


\section{A TRANSFORMAÇÃO SOCIAL COMO HORIZONTE ÉTICO-POLÍTICO}

Através dessa relação dialética entre sujeito-sociedade, evocando a ação do brasileiro, isto é, a sua práxis, na construção de sua história, que devemos pensar na transformação social como horizonte ético-político. Por mais que Darcy se declarasse socialista, de um autodenominado socialismo moreno com requintes brasileiros, "de uma civilização avançada, com esse talento do índio da convivência e da solidariedade" (RIBEIRO, 2015, p. 248), entende-se este seu socialismo no sentido da socialdemocracia, uma perspectiva trabalhista que buscava superar o capitalismo processualmente. A intervenção do Estado e a adoção de reformas democráticas no fomento a uma sociedade mais justa seriam horizontes almejados. Contudo, de forma mais enfática em O Povo Brasileiro, como resultado de todo o acúmulo intelectual, fruto de seus estudos e observações sobre a formação histórico-social brasileira, mas também do conhecimento vivo das entranhas do sistema político, Darcy aponta para a improbabilidade e limitações de uma agenda apenas reformista que almeje uma sociabilidade mais equânime, ou seja, de uma política conciliatória de classes, haja vista a elite econômica e social brasileira, num sistema que é historicamente erguido e regido por essas disparidades.

Não é impensável que a reordenação social se faça sem convulsão social, por via de um reformismo democrático. Mas ela é muitíssimo improvável neste país em que uns poucos milhares de grandes proprietários podem açambar a maior parte de seu território, compelindo milhões de trabalhadores a se urbanizarem para viver a vida famélica das favelas, por força da manutenção de umas velhas leis. Cada vez que um político nacionalista ou populista se encaminha para a revisão da institucionalidade, as classes dominantes apelam para a repressão e a força (RIBEIRO, 1995/2006, p. 23).

Ainda segundo Darcy:

O que houve e há é uma massa de trabalhadores explorada, humilhada e ofendida por uma minoria dominante, espantosamente eficaz na formulação e manutenção de seu próprio projeto de prosperidade, sempre pronta a esmagar qualquer ameaça de reforma da ordem social vigente (RIBEIRO, 1995/2006, p. 408)

Devido a essas impossibilidades, fica a necessidade de se orientar por meio de outros projetos político-societários que visem não somente reformar ou "humanizar" essa ordem social que nos conforma, mas, sim, suplantá-la. Estando a Psicologia Social brasileira circunscrita à essa realidade e suas vicissitudes, cabe a ela identificar seu papel na compreensão desta totalidade e na ação para a sua transformação, mesmo que essa ação seja limitada pelos próprias contornos da ordem social. Concordando com Guzzo (2015), põe-se a necessidade da mudança social, representada no nosso caso pela superação desse capitalismo periférico, dependente e colonial, caracterizado por MartínBaró (1986/2011) ao falar da América Central pela analogia do "garrote e da cenoura" (do porrete e 
da "diplomacia”) ou, como aponta Lacerda Júnior. (2013), constituído por processos de dependência (concebida como uma integração subserviente para fora) e barbárie (uma desintegração para dentro).

Não obstante, tais elementos nos fazem refletir sobre o próprio processo de modernização e constituição desse capitalismo à brasileira. Um processo, como afirma Coutinho (1979) - podendo ser visualizado nos próprios trechos acima de Darcy - marcado por um reformismo "pelo alto", excludente para as maiorias, e onde as mudanças não visaram transformar as estruturas e bases materiais perversas que aqui se assentaram. Pelo contrário, conforme postula Darcy, nossa classe dominante (estrangeira e interna, rural e urbana) atuou ao longo da história mais como agente de conservação e recrudescimento da ordem social, do status quo, do que para a sua transformação. Aspecto que não significa a adoção de uma postura fatalista, que desconsidere a política como espaço de lutas, e, por conseguinte, da capacidade das maiorias populares exploradas tensionarem a realidade e modifica-la.

Dessa forma, as próprias conquistas ao longo da história brasileira, com base na organização e luta desses sujeitos alijados, podem ser compreendidas como avanços, que devem ser defendidos e fortalecidos, mas também concessões de nossas elites, com a finalidade de preservação da força de trabalho para a manutenção da reprodução da lógica do capital e de nossa condição dependente (LACERDA JÙNIOR, 2013). Conforme ilustra Darcy em uma série de trechos sobre nosso processo sociocultural: "Não é por acaso, pois, que o Brasil passa de colônia a nação independente e de Monarquia à República, sem que a ordem fazendeira seja afetada e sem que o povo perceba" (RIBEIRO, 1995/2006, p. 201). Ademais, “[a]propriada por essa classe [a classe dominante local] a independência não representou nenhuma descolonização do sistema que permitisse transformar o proletariado externo em um povo para si” (RIBEIRO, 1995/2006, p. 230)

\section{POR UMA PSICOLOGIA SOCIAL MORENA: DA NINGUENDADE À BRASILIDADE}

Para explicitar as possíveis contribuições do pensamento de Darcy Ribeiro à Psicologia Social brasileira, é necessário delimitar qual a perspectiva de Psicologia Social. Cabe salientar que estamos adentrando em uma área do conhecimento de interface, com fronteiras não rígidas, sobretudo entre a Psicologia e a Sociologia, mas também agregando outras disciplinas as Ciências Sociais. Até mesmo por conta dessas múltiplas interconexões, esse complexo do saber é plural e multifacetado, agregando uma variedade de formulações teórico-conceituais.

A Psicologia Social como disciplina, historicamente, se ocupou em analisar a relação sujeitosociedade, tendo sido marcada por um modelo individualizante, calcado no método experimental de investigação, especialmente considerando seu florescimento em solo estadunidense. A 
individualização da Psicologia Social determinou os rumos deste campo em seu processo de consolidação, culminando em leituras equidistantes, minimalistas e distorcidas da dinâmica que se estabelece entre sujeito e sociedade. Conformou-se como linguagem e prática hegemônica na Psicologia, até a erupção de críticas e uma verdadeira “crise” desvelada tanto na América Latina como no continente europeu (MARTÍN-BARÓ, 1983/2017).

No cenário latino, recebeu fôlego a partir das conexões estabelecidas com outros campos de conhecimento e práticas, como: a Educação Popular de Paulo Freire, a Sociologia Crítica de Fals Borda, a Filosofia, Teologia e Psicologia da Libertação (MARTíN-BARÓ, 1986/2011) e a Psicologia Social Comunitária, (MONTERO, 2004; LANE, 2012; dentre outros) ${ }^{3}$. Configura-se, assim, um cenário bastante profícuo, tanto na produção acadêmica quanto na ação política, vistas integralmente por meio da práxis (MONTERO, 2004; LACERDA JÚNIOR, 2010; 2013; LANE, 2012).

Por conseguinte, compreendemos aqui o campo da Psicologia Social que, ao longo das últimas décadas, tem se desenvolvimento no continente latino-americano, englobando a Psicologia Social Comunitária, Psicologia da Libertação, Psicologia Política e Psicologia Social em uma perspectiva crítica, orientada para a transformação da realidade social. A despeito de diferentes leituras que compõem este amplo campo, consideramos que o diálogo a partir da obra de Darcy encontra mais proficuidade com estas vertentes da Psicologia, que partem de uma perspectiva materialista histórica e dialética da relação sujeito-sociedade, e, portanto, compreendem o processo formação da consciência, dos processos de subjetivação, e constituição da identidade como produtos oriundos das relações que homens estabelecem entre si e destes com a realidade concreta na qual se inserem e são herdeiros, como membros do gênero humano. Em suma, é, sobretudo, a partir dessa concepção de Psicologia Social que tentaremos estabelecer um diálogo com o pensamento de Darcy Ribeiro.

A partir destas contribuições iniciais, entende-se que a conformação da Psicologia Social brasileira, assim como Darcy intentou com o pensamento social, passa primordialmente pelo aprofundamento da compreensão acerca da nossa concretude histórica, dos processos objetivos de formação do ser brasileiro. Uma Psicologia Social brasileira que, como Arrruti (1997) constata para a Antropologia, nos tome como parâmetro, isto é, conceba o Brasil e o brasileiro, como seus sujeitos/objetos, ao mesmo tempo em que assuma uma consciência de si enquanto brasileira. Afinal, assim como o brasilíndio se viu desamparado de identidade própria, muitas das críticas que se tem à Psicologia, e em parte a determinadas vertentes da Psicologia Social brasileira, como o seu individualismo, ahistoricidade, visão homeostática e descontextualizada e a sua

\footnotetext{
${ }^{3}$ No Brasil, também podem ser ressaltadas as inciativas e trabalhos de Dante Moreira Leite e Manuel Bomfim (este último, inclusive, bastante citado por Darcy durante sua vida e que exerce influência em seu pensamento), que já pensavam de maneira percursora uma psicologia social descolonizada e própria de Brasil
} 
dependência/colonização ontológica, epistemológica e metodológica (MARTÍN-BARÓ, 1986/2011), decorrem da sua própria ninguendade intelectual, ao se consolidarem na sociedade brasileira, agregando algumas de suas características.

Assentados no materialismo histórico-dialético de Darcy, é a partir da concretude e seu caráter dinâmico, isto é, do modo de produção e reprodução da vida material, que se dá nossa formação identitária, conformando determinações reflexivas, contrapondo-se a leituras essencialmente culturalistas ou personalistas, e, principalmente, fugindo de análises casuísticas e dicotomizadas sobre objetivo e subjetivo, real e abstrato, eu e o outro. Não fazendo isto, corre-se o risco de descaracterização daquilo que se pretende entender, que é justamente esse brasileiro, que é plural, diverso, e cujas singularidades se dão - e, portanto, devem ser compreendidas - em meio à nossa totalidade social. Incorrendo nessa lógica, outra possível consequência é a utilização da Psicologia Social como argumento ou ferramenta de perpetuação de relações de segregação, normatização, opressão e dominação, do mesmo modo que parte da tradição psicológica no Brasil (SPINK; SPINK, 2006; LACERDA JÚNIOR., 2010; 2013); em suma, como mais um dos moedores e pás que macetam e ceifam essa gente já gastada.

Assim, é possível contribuir para a reflexão do próprio papel da Psicologia e da Psicologia Social brasileira na compreensão de nós mesmos como sujeitos. Sobre a Psicologia, de modo geral, são possibilitadas reflexões críticas acerca do seu histórico de desenvolvimento e consolidação dependente, assentado, em grande parte, num ideário individualista hegemônico que serviu e serve de sustentação para ideologias dominantes, ao localizar a gênese de possíveis problemas que são eminentemente sociais, históricos e culturais nos próprios indivíduos, sobretudo em sua dimensão psíquica, acarretando na sua culpabilização e/ou ampla responsabilização pelas situações em que se encontram (LACERDA JÚNIOR., 2013).

Tais pressupostos podem ser traduzidos na crítica à Psicologia feita por Dimenstein (2000), de que se almeja modificar o indivíduo preservando a ordem social ou acreditando que mudando o indivíduo, muda-se automaticamente a ordem social. Guzzo (2015) também fortalece essa crítica, para quem a Psicologia enfatizou a "alma atingida", desconsiderando o "corpo sofredor", isto é, as questões objetivas da vida cotidiana, assim como Lacerda Júnior. (2010), que aponta como a Psicologia explicou problemas da humanidade olhando apenas para o que se passa dentro da cabeça das pessoas. Observa-se uma absolutização da individualidade como condição universal do ser humano e uma naturalização do social que contribuem para a cristalização e consequentes manutenção e reprodução da ordem vigente (GUZZO, 2010).

Reside, então, a premência de compreender essas bases concretas, materiais, de conformação dos sujeitos, tomando-os como seres coletivos, ou como aponta Lane (2012), um ser humano em 
movimento, que não é somente um mero receptor ou produto da sociedade, mas um ser ativo frente às suas próprias condições de vida e existência; aquele que forja sua própria história, mesmo que não sendo sob suas próprias condições, dando sentido ao meio e aos objetos que o cerceiam, ao mesmo tempo em que transforma a si e o mundo através de sua atividade, isto é, a partir da práxis humana.

Isso nos leva à compreensão de sujeitos e realidade sem cair em determinismos tanto sociologizantes quanto psicologizantes, evitando concebê-los como meras determinações do social, nem como indivíduos isolados que se autorrealizam, frutos simplesmente de suas variáveis biológicas, genéticas e/ou psicológicas. Ou seja, em consonância com Martín-Baró (1983/2017) e Lane (2012), essa relação sujeito-sociedade é tomada como objeto da Psicologia Social. O próprio Darcy deixa isso claro quando postula que nossa construção identitária é uma conjunção de eventos biológicos (provenientes da mestiçagem), sociais (relacionados às formas de nossa colonização e à consequente deculturação) e psicológicos (referentes a essa busca por uma identidade ancorada na ninguendade e suas implicações) (ARRUTI, 1997).

Trata-se, portanto de observamos nossa complexidade a partir de um prisma totalizante, buscando não cair em dois polos antagônicos: (a) um relativismo irracionalista que nos impeça de falar do Brasil, inserido em uma ordem mundial, ou do brasileiro como ser humano (sendo estas categorias, por princípio, universalizantes); (b) ou uma perspectiva absolutista que desconsidere especificidades e singularidades dos diferentes contextos, sujeitos e processos históricos, como o que fizeram as leituras etnocêntricas nas ciências sociais (MIGLIEVICH-RIBEIRO, 2011; LACERDA JÚNIOR. 2013). É justamente isso que Darcy visa romper quando constata nossa unicidade enquanto povo, diferente de todos os outros, "uma nova Roma [...] tardia e tropical” (RIBEIRO, 1995/2006, p. 411), calcada em nossa diversidade antropofágica, classista, racista e gestada etnicamente.

Afinal, ao tratarmos do ser humano como ser social, estamos falamos de um sujeito que tem classe, cor/raça/etnia, gênero, cuja grande parcela aqui ainda sente fome, sofre com a falta de acesso a recursos que lhe possibilite uma vida digna e com entrelaçamentos com os dispositivos e estruturas da sociedade. Mais importante, um sujeito permeado por uma história, que lhe atribui materialidade e significação, ao mesmo tempo em que é a concretização de sua ação. Todavia, observa-se na Psicologia Social e Psicologia brasileiras, muitas das vezes, uma incongruência entre esse ser real no nosso caso, o brasileiro - na sua conformação dialética singular-particular-universal (PASQUALINI; MARTINS, 2015), e as epistemes que supostamente se propõem a abarcá-lo. Como exemplos, temos algumas vertentes teóricas "psicossociológicas" que ancoram este ser numa busca ad eternum por uma felicidade plena inatingível e alienante. Ou que ainda concebem e analisam o brasileiro primordialmente a partir de "padrões" e atributos não condizentes com grande parcela da 
população, isto é: homem, branco, pertencentes a um estrato socioeconômico da classe média ou alta etc.

Conforme postula Darcy na sua análise da formação e sentido do Brasil, clarifica-se o entendimento da realidade como processo histórico (em contínua construção) permeado por constantes tensões/contradições, o que contribui para a sua desnaturalização. Sendo este contexto produzido por quem nele se insere, ao mesmo tempo em que também se produz, seria responsabilidade da Psicologia Social "recuperar o indivíduo na intersecção de sua história com a história de sua sociedade" (LANE, 2012, p. 13), ao invés de fomentar perspectivas analíticas dicotômicas/fragmentárias acerca da relação indivíduo-sociedade.

Cabe, então, à Psicologia Social compreender o cenário no qual se insere e os sujeitos sob os quais se assenta, aceitando também que nenhuma disciplina isolada, mesmo que fronteiriça, é capaz de abarcar essa totalidade, nem os sujeitos em sua complexidade. Busca-se, assim, seguir o próprio exemplo de Darcy, que empregou esforços contínuos de compreensão e expressão da realidade brasileira nas mais diversas formas (pela arte, ciência, ensino, política etc.), transitando por várias áreas do conhecimento (Antropologia, Sociologia, dentre outras) e se valendo de arcabouços teóricoconceituais contextualizados à luz de nossa realidade, numa perspectiva totalizante, em detrimento de uma utilização acrítica e colonizada intelectualmente.

Tal exemplo bastante se assemelha com a proposta do realismo crítico formulada por MartínBaró (1987/2017), de onde a realidade concreta prescinde as ideias, em contraposição a um idealismo metodológico, quando se busca encaixar a realidade em formulações abstratas pré-concebidas, isto é, uma adequação do real ao ideal, o que, muitas das vezes, gera formulações e práticas descontextualizadas. Como consequência, rompe-se com visões ingênuas de uma suposta autossuficiência que se tem, principalmente, na Psicologia, mas também na Psicologia Social, e da crença de que disciplinas particularizadas do conhecimento sejam capazes de compreender o ser humano em sua totalidade, bem como contribuir de forma uníssona para a transformação desta realidade (LACERDA JÚNIOR, 2010).

A partir destas pressuposições intentamos, ainda que de forma inicial, reforçar os espaços existentes para o estabelecimento de diálogos horizontais e permanentes da Psicologia Social com outras áreas do saber e campos de práticas, como as outras disciplinas das Ciências Sociais e o vasto acúmulo de conhecimento proveniente do pensamento social brasileiro, estabelecendo relações de contribuição mútuas para o enriquecimento de ambas. Afinal, a realidade que visam pesquisar e transformar, guardadas as devidas proporções e ênfases, bem como os sujeitos que dela fazem parte e a constituem, são, em concretude, os mesmos. 
Obviamente que falar da Psicologia Social e do pensamento social brasileiro como uníssonos contradiz suas próprias pluralidades. Nesse sentido, entendemos que o pensamento darcyniano poderá não ofertar tantas contribuições significativas para determinadas tradições psicossociológicas que não compartilhem de suas premissas, obstaculizando diálogos. Contudo, tais constatações não diminuem a necessidade de um maior entrelaçamento entre a Psicologia Social, os postulados de Darcy, bem como de inúmeros outros autores do pensamento social brasileiro, resguardando suas especificidades e a premência de se estabelecer coerências ontológica, epistemológica e metodológica entre eles.

Levando em consideração a discussão apresentada até aqui, uma última implicação que gostaríamos de reiterar é sobre a práxis psicossociológica. A partir dos diálogos estabelecidos, colocamos a necessidade de a Psicologia Social brasileira se orientar pela transformação social, contextualizando-a num panorama de constituição do Brasil como país-nação dentro da ordem capitalista mundial. Dessa forma, compreendemos as limitações impostas por nossa configuração social e modos de sociabilidade, perpassados pelo nosso histórico de exploração, colonização e dependência, assim como os constrangimentos enfrentados pela própria prática profissional, limitada por essa base concreta e também simbólica. Em consonância com Yamamoto (2007), é a partir destas reflexões que se torna possível sair de posições antagônicas frequentes na área e intimamente prejudiciais: uma que veste a Psicologia Social, a Psicologia Social Comunitária e outras de um véu de messianismo, de que conseguiriam por si só propiciar a salvação daqueles(as) os(as) quais abarcam; e outra, que cai num fatalismo acerca das possibilidades de crítica e atuação, gerando desresponsabilizações e imobilismos.

Não obstante, estando a práxis acoplada à realidade social apresentada e, portanto, dos meios que a conformam e que dela resultam, suas ferramentas encontram-se localizadas nessa própria realidade, seus sujeitos, grupos e comunidades (MARTÍN-BARÓ, 1985/1996). Tomando a práxis como critério de verdade, com vistas a processos vivenciais mais equânimes, é necessário considerar e implicar os sujeitos nos processos de produção de conhecimento e atuação, entendendo a própria a Psicologia Social e a ciência em geral como práticas sociais. Afinal, se tomamos estes sujeitos como seres ativos em sua própria história e condição de vida, é coerente e esperado que estes sejam os protagonistas nos processos em que vivenciam e forjam. Trata-se de reforçar a centralidade deste brasileiro, com seus sincretismos e idiossincrasias, na produção de conhecimento e ação sobre uma realidade que é sua. 
Dessa forma, é possível pensar numa 'Psicologia Social morena', que supere os dilemas oriundos da sua ninguendade ${ }^{4}$, por meio da aceitação de sua brasilidade. Uma Psicologia Social brasileira que, assim como necessita o seu povo, volte-se cada vez mais para si, vivendo seu próprio projeto intelectual/acadêmico e prático e rompa com a sua miséria de dependência colonial (MARTÍN-BARÓ, 1986/2011), conformada desde a feitoria escravista que aqui se fez, e que nos tomou, desde já, como meras fontes de matéria-prima e mão de obra. Ou seja, um "proletariado externo" (RIBEIRO, 1995/2006, p. 404), incapaz também de pensar por si mesmo.

Que arrombemos, portanto, alguns dos grilhões intelectuais e acadêmicos que ainda nos alijam e que a Psicologia Social brasileira e latino-americana em geral seja fortalecida ao se nutrir da "razão iracunda" de Darcy Ribeiro (VASCONCELLOS, 2015), dentre outros pensadores; que continue a ser atravessada por uma inquietude, insubmissão e indignação ao não aceitar nossa condição desigual como condição natural ou um mero destino.

\section{CONSIDERAÇÕES FINAIS}

O presente trabalho consistiu em um movimento inicial de demonstração de algumas contribuições possibilitadas pelo diálogo da Psicologia Social brasileira com o pensamento de Darcy Ribeiro. Por conta dos próprios entraves inerentes a uma tentativa de sintetizar um campo do saber e de práticas plural e uma obra e pensamento tão abrangentes num espaço como esse, torna-se incipiente, perpassado por uma série de limitações que indicam a necessidade de sua continuação, com complementariedades, aprofundamentos e contínuas aproximações com outras disciplinas das Ciências Sociais e autores do pensamento social brasileiro. O próprio pensamento de Darcy convoca a inúmeras reelaborações e aprofundamentos, em decorrência de suas limitações contextuais e temporais, a partir do momento em que consideramos o movimento contínuo de conformação da realidade brasileira e do conhecimento sobre esta.

Nesse sentido, o estudo que aqui se revela caracteriza-se como um convite, almejando sinalizar caminhos ainda inexplorados ou percorridos timidamente na Psicologia Social brasileira; movimento este em consonância com vários autores e perspectivas da Psicologia Social crítica latinoamericana. Assim, podemos assentar contribuições que incidem não só em processos de descolonização das formulações teórico-conceituais e metodológicas, mas, principalmente, na

\footnotetext{
${ }^{4}$ Denominação feita por Arruti (1997) para a Antropologia e que tomamos de empréstimo para caracterizar a Psicologia Social brasileira. Diz respeito ao dilema do brasilíndio ou do neobrasileiro, que ao ser dois, a mistura entre dominador e dominado, é também ninguém; que renega suas origens indígenas e é renegado pelo colonizador português. Assim, almeja-se uma Psicologia Social que, ao invés de intentar não ser si mesma, fugindo de sua brasilidade, compreenda suas particularidades.
} 
qualificação do entendimento dessa realidade que se põe à nossa volta, com vistas também à sua modificação. De certo modo, o presente exercício reflexivo encontra-se relacionado com o questionamento sobre que tipo de Psicologia Social queremos. Questão que obviamente toca nas fundamentações ontológicas, epistemológicas e metodológicas, ou seja, quem são esses sujeitos e essa realidade que supostamente visamos compreender e como os abarcamos. E além disso, nos obriga continuamente a um questionamento sobre as dimensões ética e política envolvidas em nosso quefazer profissional.

Portanto, assim como Darcy postulou que "não há lugar no mundo melhor para se construir um país, do que aqui" 5 , ninguém melhor que o próprio brasileiro - ao forjar e ser forjado nessa realidade - e sua inventividade para desvelar e compreender o processo de formação deste paísnação; um processo intricado e calcado no sangue e suor de muitos, do qual fazemos parte e somos perpassados ao vivenciarmo-lo cotidianamente e trazermos em nossas constituições suas agruras, mas também algumas de suas potencialidades e uma incontável possibilidade de porvires.

Abrem-se portas para uma produção de saberes contextualizada, dialogando com o conhecimento proveniente de outras terras e tempos, mas que se desprenda de nossos resquícios de dependência/colonização e amarras de subordinação intelectual. Uma produção que não se ocupe apenas com a leitura da realidade, mas que se comprometa com a sua transformação. Finalmente, uma produção que tome os daqui não apenas em posições coadjuvantes e/ou de meros leitores/observadores da realidade, mas como os atores, roteiristas e diretores desta história viva que, ao contrário do que nos fazem crer, lhes pertence; nos pertence.

\section{REFERÊNCIAS}

ARRUTI, J. M. Uma antropologia Mameluca a partir de Darcy Ribeiro, 1995: O Povo Brasileiro. Revista da Faculdade de Letras, v. 21, n. 1, p. 301-12, 1997.

COUTINHO, C. N. A democracia como valor universal. Encontros com a Civilização Brasileira, v. 9, p. 33-48, 1979.

DIMENSTEIN, M. D. A cultura profissional do psicólogo e o ideário individualista: implicações para a prática no campo da assistência pública à saúde”. Estudos de Psicologia, v. 5, n. 1, p. 95$121,2000$.

${ }^{5}$ Fala proferida por Darcy Ribeiro no programa de entrevistas "Roda Viva", em 20 de junho de 1988. 
GUZZO, R. S. L. Da opressão à libertação: Uma perspectiva urgente para a Psicologia - a conclusão de um projeto, a abertura de perspectiva". In: GUZZO, R. S. L; LACERDA JR., F. (Orgs.). Psicologia e sociedade: Interfaces no debate sobre a questão social. Campinas: Alínea, 2010, p. 13-18.

GUZZO, R. S. L. Critical psychology and the American continent: from colonization and domination to liberation and emancipation". In: PARKER, I. (Org.) Handbook of critical psychology. New York: Routledge, 2015, p. 406-414

LACERDA JÚNIOR, F. Psicologia para fazer a crítica? Apologética, individualismo e marxismo em alguns projetos psi. 2010. Tese (Doutorado em Psicologia) - Programa de Pós-Graduação em Psicologia, Pontifícia Universidade Católica de Campinas, Campinas. 2010.

LACERDA JÚNIOR, F. Capitalismo dependente e a psicologia no Brasil: das alternativas à psicologia crítica. Teoría y crítica de la psicología, v. 3, 216-263, 2013.

LANE, S. T. M. A Psicologia Social e uma nova concepção do homem para a Psicologia. In: LANE, S. T. M.; CODO, W. (Orgs.). Psicologia Social: O homem em movimento. São Paulo: Editora Brasiliense, 2012, p. 10-19.

MARTÍN-BARÓ, I. Entre o indivíduo e a sociedade. In: LACERDA JR., F. (Org.). Crítica e libertação na Psicologia: estudos psicossociais. Petrópolis: Vozes, 1983/2017, p. 101-161.

MARTÍN-BARÓ, I. 1985/1996. “O papel do psicólogo”. Estudos de Psicologia, v. 2, n. 1, 7-27.

MARTÍN-BARÓ, I. Conflito social e ideologia científica: do Chile a El Salvador. In: LACERDA JÚNIOR, F. (Org.). Crítica e libertação na Psicologia: estudos psicossociais. Petrópolis: Vozes, 1985/2017, p. 30-54.

MARTÍN-BARÓ, I. Para uma Psicologia da Libertação. In: GUZZO, R. S. L.; LACERDA JÚNIOR, F. (Orgs.). O resgate da Psicologia da Libertação. Campinas: Alínea, 1986/2011, p. 181-198.

MARTÍN-BARÓ, I. O desafio popular à Psicologia Social na América Latina. In: LACERDA JÚNIOR, F. (Org.). Crítica e libertação na Psicologia: estudos psicossociais. Petrópolis: Vozes, 1987/2017, p. 66-88.

MIGLIEVICH-RIBEIRO, A. 2009. A antropologia dialética de Darcy Ribeiro em "O povo brasileiro". SINAIS - Revista Eletrônica - Ciências Sociais, v. 6, n. 1, p. 52-72, 2009. 
MIGLIEVICH-RIBEIRO, A. Darcy Ribeiro e o pensamento crítico latino-americano: diálogos com a epistemologia póscolonial. SINAIS - Revista Eletrônica - Ciências Sociais, v. 9, n. 1, p. 12-31, 2011.

MONTERO, M. Relaciones Entre Psicología Social Comunitaria, Psicología Crítica y Psicología de la Liberación: Uma Respuesta Latinoamericana. Psykhe, v. 13, n. 2, p. 17-28, 2004.

PASQUALINI, Juliana Campregher; MARTINS, Lígia Márcia. Dialética singular-particularuniversal: implicações do método materialista dialético para a psicologia. Psicol. Soc., Belo Horizonte, v. 27, n. 2, p. 362-371, 2015.

RIBEIRO, Darcy. O povo brasileiro: A formação e o sentido do Brasil. São Paulo: Companhia das Letras, 1995/2006.

RIBEIRO, Darcy. O Brasil como problema. São Paulo: Global, 2015

SPINK, M. J. P.; SPINK, P. K. A Psicologia Social na atualidade. In: JACÓ-VILELA, A. M.; FERREIRA, A. A. L.; PORTUGAL, F. T. (Orgs.). História da Psicologia: rumos e percursos. Rio de Janeiro: Nau Editora, 2006, p. 565-596.

VASCONCELLOS, G. F. Darcy Ribeiro: A razão iracunda. Florianópolis: UFSC, 2015.

YAMAMOTO, O. H. Políticas sociais, "terceiro setor" e "compromisso social": perspectivas e limites do trabalho do psicólogo. Psicol. Soc., v. 19, n. 1, p. 30-37, 2007.

$\begin{array}{ll} & \text { Recebido em: 20-11-2017 } \\ \text { Histórico } & \text { Revisado em: 19-6-2018 } \\ & \text { Aceito em: 6-7-2018 }\end{array}$

